\title{
PENERAPAN MODEL PEMBELAJARAN GROUP INVESTIGATION (GI) PADA MATERI PERSAMAAN GARIS LURUS DITINJAU DARI KEMANDIRIAN BELAJAR SISWA SEKOLAH MENENGAH PERTAMA
}

\author{
Venty Meilasari ${ }^{1}$ \\ ${ }^{1}$ Program Studi Pendidikan Matematika, STKIP Muhammadiyah Kotabumi \\ email: ventymeilasari@gmail.com
}

\begin{abstract}
This research aimed to find out: (1) which one providing better mathematics learning outcomes, GI model or direct learning model, (2) which one providing better mathematics learning outcomes, the high, medium or low learning independence students, (3) interaction between learning models and learning independence on mathematics learning outcomes. This research used the quasiexperimental research method with $2 \times 3$ factorial design. The population were all students of the $8^{\text {th }}$ class of SMP Negeri 6 Surakarta on academic year 2015/2016. The sample was taken using purposive sampling. The instruments used were learning independence questionnaire and mathematics learning outcomes test. The proposed hypothesis of the research were analyzed by using two-way analysis of variance. The conclusions of this research were as follow. (1) GI model provided better mathematics outcomes than direct learning model. (2) The high learning independence student had better mathematics learning outcomes than medium and low learning independence students, and the medium had as good as low learning independence students. (3) there was no interaction between learning models and learning independence on mathematics learning outcomes.
\end{abstract}

Keywords: group investigation, direct learning model, mathematics learning outcomes.

\section{A. PENDAHULUAN}

Matematika adalah mata pelajaran yang penting untuk dipelajari. Selain menjadi dasar bagi mata pelajaran lainnya, Cornelius (dalam Abdurahman, 2010:253) mengemukakan alasan perlunya belajar matematika, yaitu karena matematika merupakan: (a) sarana berpikir yang jelas dan logis; (2) sarana memecahakan masalah dalam kehidupan sehari-hari; (c) sarana mengenal pola hubungan dan generalisasi pengalaman; (d) sarana untuk mengembangkan kreativitas; dan (5) sarana untuk meningkatkan kesadaran terhadap perkembangan budaya. Mengingat banyaknya manfaat yang diperoleh dari belajar matematika, seyogyanya siswa dapat memiliki penguasaan matematika dengan baik. Salah satu indikator yang dapat menjadi tolak ukur penguasaan matematika siswa adalah hasil belajar matematika siswa.

Pada kenyataannya, hasil belajar matematika yang dicapai siswa masih rendah. Hasil ujian nasional (UN) Sekolah Menengah Pertama (SMP) tahun 2014 pada program PAMER UN menunjukkan bahwa 
matematika menduduki peringkat terbawah dibandingkan dengan tiga mata pelajaran yang lain, dengan pencapaian rerata nilai 6,89. Pada tingkat kota/kabupaten nilai matematika siswa SMP negeri di kota Surakarta hanya mencapai rerata nilai 6,40 . Hal ini mengindikasikan bahwa banyak indikator pembelajaran yang memiliki daya serap rendah. Indikator yang memiliki daya serap paling rendah adalah materi persamaan garis lurus yang hanya mencapai $45,07 \%$. Pencapaian yang rendah pada materi persamaan garis lurus juga dialami oleh siswa Sekolah Menengah Pertama Negeri 6 Surakarta. Berdasarkan hasil UN, diperolah bahwa hanya $45,11 \%$ siswa yang mampu menjawab benar pertanyaan yang berkaitan dengan materi persamaan garis lurus.

Pencapaian yang rendah disebabkan oleh beberapa faktor. Slameto (2010:54) menyatakan bahwa terdapat dua faktor yang memengaruhi hasil belajar siswa, yaitu faktor eksternal dan faktor internal. Adapun salah satu faktor yang termasuk dalam faktor eksternal adalah model pembelajaran yang digunakan guru dalam pembelajaran. Berdasarkan hasil oberservasi, diketahui bahwa guru di SMP Negeri 6 Surakarta masih menggunakan model pembelajaran belum melibatkan siswa secara aktif. Siswa hanya menerima informasi dari guru. Dalam pembelajaran, belum terjadi interaksi yang baik antara guru dengan siswa maupun siswa dengan siswa.
Salah satu model pembelajaran yang dapat menjadi solusi adalah model pembelajaran kooperatif. Model pembelajaran kooperatif merupakan model pembelajaran yang mengondisikan siswa untuk bekerja sama dalam memahami materi pembelajaran. Dengan belajar bersama teman sebaya diharapkan siswa akan lebih merasa nyaman untuk mendiskusikan pelajaran. Menurut Lie (2010:12) pembelajaran kooperatif merupakan sistem pembelajaran yang memberi kesempatan kepada siswa dengan sesama siswa dalam tugas-tugas yang terstruktur. Adapun salah satu tipe model pembelajaran kooperatif adalah group investigation (GI).

Model pembelajaran kooperatif tipe GI sebagai salah satu model pembelajaran kooperatif yang melibatkan peserta didik untuk mandiri sejak dari perencanaan, baik dalam cara untuk mempelajarinya melalui investigasi. Menurut Sugiyanto (2009:46) pada model ini siswa dilibatkan sejak perencanaan, penentuan topik, maupun cara untuk mempelajari investigasinya. Siswa dituntut untuk memiliki kemampuan yang baik dalam komunikasi maupun ketrampilan proses berkelompok. Selanjutnya Slavin (2005:218 - 220) menyatakan bahwa dalam model pembelajaran GI terdapat enam tahap pembelajaran, yaitu: (a) identifikasi topik; (b) perencanaan investigasi; (c) pelaksanaan investigasi; (d) penyiapan laporan akhir; (e) presentasi laporan akhir; dan (f) evaluasi 
pencapaian. Dengan terlibatnya siswa secara aktif dalam pembelajaran, belajar menjadi lebih bermakna sehingga penerapan model pembelajaran GI diharapkan dapat meningkatkan hasil belajar matematika siswa. Hal ini didukung oleh hasil penelitian Solikhah (2014) menyatakan bahwa pembelajaran GI memberikan prestasi belajar yang lebih baik dibandingkan dengan pembelajaran langsung.

Keterlibatan siswa yang besar dalam pembelajaran GI menjadikan kemandirian belajar merupakan suatu unsur yang penting. Kemandirian berarti hal atau keadaan yang dapat berdiri sendiri tanpa bantuan orang lain. Meskipun kemandirian berarti dapat berdiri sendiri, kemandirian belajar tidak berarti belajar secara sendiri. Kemandirian dalam belajar menurut Wedemeyer (dalam Rusman, 2010:354) perlu diberikan kepada siswa supaya mereka mempunyai tanggung jawab dalam mengatur dan mendisiplinkan dirinya dalam mengembangkan kemampuan belajar atas kemauan sendiri.

Selanjutnya Song dan Hill (2007: 31— 32) menyatakan kemandirian belajar terdiri dari beberapa aspek, yaitu: a) atribut pribadi merupakan aspek yang berkenaan dengan motivasi belajar, penggunaan sumber belajar, dan strategi belajar; b) proses merupakan aspek yang berkaitan dengan kemandirian belajar siswa dalam proses pembelajaran yang meliputi perencanaan, monitoring, serta evaluasi belajar; c) fokus dari konteks adalah faktor lingkungan dan bagaimana faktor tersebut memengaruhi tingkat kemandirian belajar. Faktor tersebut antara lain, structure dan nature of task.

Siswa yang memiliki kemandirian belajar yang tinggi memiliki kontrol yang kuat terhadap dirinya untuk merencanakan, memonitoring, mengontrol, dan mengevaluasi proses belajarnya. Dengan manajemen yang baik dari siswa sehingga kemandirian belajar memberikan pengaruh terhadap hasil belajar matematika yang dicapai siswa. Hal ini didukung oleh penelitian Fitriana (2010) yang menyimpulkan bahwa prestasi belajar siswa yang mempunyai kemandirian tinggi lebih baik daripada siswa yang mempunyai kemandirian belajar sedang dan rendah, serta siswa yang mempunyai kemandirian belajar sedang mempunyai prestasi belajar yang lebih baik dari pada siswa yang mempunyai kemandirian belajar rendah.

Berdasarkan uraian di atas, akan dilakukan penelitian yang bertujuan untuk mengetahui: 1) manakah yang lebih baik, hasil belajar matematika siswa yang diberi model GI atau model pembelajaran langsung; 2) manakah yang memiliki hasil belajar yang lebih baik, siswa dengan kemandirian belajar tinggi, sedang, atau rendah; dan 3) adakah interaksi antara model pembelajaran dan kemandirian belajar terhadap hasil belajar matematika siswa. 


\section{B. METODOLOGI PENELITIAN}

Penelitian ini merupakan penelitian eksperimental semu dengan desain penelitian faktorial $2 \times 3$. Populasi dalam penelitian adalah seluruh siswa kelas VIII SMP Negeri 6 Surakarta Tahun Pelajaran 2015/2016. Adapun teknik pengambilan sampel yang digunakan adalah purposive sampling. Sampel yang terpilih adalah kelas VIII C dan VIII E.

Adapun teknik pengumpulan data meliputi metode dokumentasi yang mengumpulkan data kemampuan awal siswa berupa data hasil mid semester ganjil matematika tahun pelajaran 2015/2016, metode tes yang mengumpulkan data hasil belajar matematika, dan metode angket yang mengumpulkan data kemandirian belajar. Instrumen penelitian berupa tes hasil belajar dan angket kemandirian belajar. Sebelum diujikan kepada siswa dala sampel, instrumen divalidasi ke para ahli sesuai bidang pendidikan matematika untuk tes, dan bidang psikologi untuk angket. Selanjutnya kedua instrumen diujicobakan ke siswa diluar sampel untuk kemudian dianalisis tingkat kesukaran dan daya pembeda untuk instrumen tes, konsistensi internal untuk angket, dan kemudian diuji reliabilitas instrumen.

Teknik analisis data menggunakan analisis variansi dua jalan dengan sel tak sama. Namun sebelumnya dilakukan terlebih dahulu uji prasyarat analisis yaitu uji normalitas dengan metode Lilliefors dan homogenitas dengan uji Bartlett. Selanjutnya digunakan uji Scheffe' untuk uji lanjut pasca anava.

\section{HASIL PENELITIAN}

Penelitian dilaksanakan pada semester ganjil tahun pelajaran 2015/2016. Adapun data hasil penelitian dapat dilihat pada Tabel 1 berikut.

Tabel 1

Rangkuman Rerata Marginal pada MasingMasing Sel

\begin{tabular}{ccccc}
\hline \multirow{2}{*}{$\begin{array}{c}\text { Model } \\
\text { Pembelajaran }\end{array}$} & $\begin{array}{c}\text { Kemandirian Belajar } \\
\left(\mathrm{b}_{1}\right)\end{array}$ & $\begin{array}{c}\text { Rerata } \\
\left(\mathrm{b}_{2}\right)\end{array}$ & $\begin{array}{c}\text { rendah } \\
\left(\mathrm{b}_{3}\right)\end{array}$ & $\begin{array}{c}\text { Margin } \\
\text { al }\end{array}$ \\
\hline GI $\left(a_{1}\right)$ & 70,625 & 62,667 & 61,52 & 64,424 \\
Langsung $\left(a_{2}\right)$ & 68,75 & 53,5 & 50 & 56,167 \\
\hline $\begin{array}{c}\text { Rerata } \\
\text { Marginal }\end{array}$ & 69,688 & 59 & 54,608 & \\
\hline
\end{tabular}

Berdasarkan uji normalitas dan homogenitas yang dilakukan diperoleh bahwa data berasal dari populasi yang berdistribusi normal dan homogen. Selanjutnya dilakukan uji hipotesis dengan menggunakan anava dua jalan dengan sel tak sama. Rangkuman anava dua jalan dengan sel tak sama disajikan pada Tabel 2 berikut.

Tabel 2

Rangkuman Anava Dua Jalan dengan Sel Tak Sama

\begin{tabular}{|c|c|c|c|c|c|c|}
\hline $\begin{array}{l}\text { Sumb } \\
\text { er }\end{array}$ & JK & $\mathrm{dk}$ & RK & $\mathrm{F}_{\mathrm{obs}}$ & $\mathrm{F}_{a}$ & Kep \\
\hline A & 814,446 & 1 & 814,446 & 4,551 & 4,02 & $\begin{array}{c}\mathrm{H}_{0 \mathrm{~A}} \\
\text { ditolak }\end{array}$ \\
\hline B & 2137,791 & 2 & 1068,895 & 5,973 & 3,17 & $\begin{array}{c}\mathrm{H}_{0 \mathrm{~B}} \\
\text { ditolak }\end{array}$ \\
\hline $\mathrm{AB}$ & 242,772 & 2 & 121,386 & 0,678 & 3,17 & $\begin{array}{c}\mathrm{H}_{0 \mathrm{AB}} \\
\text { diterima }\end{array}$ \\
\hline Galat & 9842,708 & 55 & 178,958 & - & - & - \\
\hline Total & 13037,717 & 60 & - & - & - & - \\
\hline
\end{tabular}


Berdasarkan Tabel 2, dengan $\alpha=$ 0,05 diperoleh hasil: (1) $H_{0 \mathrm{~A}}$ ditolak yang berarti terdapat perbedaan hasil belajar matematika siswa yang diberi perlakuan model pembelajaran GI dan pembelajaran langsung. Berdasarkan rerata hasil belajar matematika, dapat disimpulkan bahwa hasil belajar matematika siswa yang diberi perlakuan model GI lebih baik daripada siswa yang diberi model pembelajaran langsung; (2) $H_{0 \mathrm{~B}}$ ditolak, artinya terdapat perbedaan hasil belajar matematika antara siswa dengan kemandirian belajar tinggi, sedang, dan rendah. (3) $H_{0 \mathrm{AB}}$ diterima artinya tidak terdapat interaksi antar model pembelajaran dan kemandirian belajar terhadap hasil belajar matematika.

Karena $\mathrm{H}_{0 \mathrm{~B}}$ ditolak, maka dilanjutkan dengan uji komparasi ganda antar kolom. Adapun hasilnya disajikan pada Tabel 3 berikut.

Tabel 3

Hasil Uji Komparasi Rerata Antar Kolom

\begin{tabular}{ccccc}
\hline No & $\mathrm{H}_{0}$ & $\mathrm{~F}_{\text {obs }}$ & $2 \mathrm{~F}_{(0,05 ; 2 ; 5)}$ & $\begin{array}{c}\text { Keputusan } \\
\text { Uji }\end{array}$ \\
\hline 1 & $\mu_{.1}=\mu_{.2}$ & 6,227 & 6,34 & $\mathrm{H}_{0}$ ditolak \\
2 & $\mu_{\cdot 2}=\mu_{.3}$ & 1,198 & 6,34 & $\mathrm{H}_{0}$ diterima \\
3 & $\mu_{.1}=\mu_{.3}$ & 11,295 & 6,34 & $\mathrm{H}_{0}$ ditolak \\
\hline
\end{tabular}

Berdasarkan Tabel 3 dapat disimpulkan bahwa: (1) hipotesis pertama ditolak, berarti terdapat perbedaan hasil belajar matematika antara siswa dengan kemandirian tinggi dan sedang. Berdasarkan rerata marginal hasil belajar siswa dengan kemandirian belajar tinggi lebih baik daripada siswa berkemandirian belajar sedang; (2) hipotesis kedua diterima, berarti tidak terdapat perbedaan hasil belajar antara siswa berkemandirian belajar sedang dan rendah; (3) hipotesis ketiga ditolak, berarti terdapat perbedaan hasil belajar antara siswa berkemandirian belajar tinggi dan rendah. Berdasarkan rerata marginal hasil belajar siswa berkemandirian belajar tinggi lebih baik daripada siswa berkemandirian belajar rendah.

\section{PEMBAHASAN}

Hasil analisis data untuk hipotesis pertama dengan anava dua jalan dengan sel tak sama, diperoleh bahwa hasil belajar matematika siswa yang diberi model pembelajaran GI lebih baik daripada siswa yang diberi model pembelajaran langsung. Hal ini disebabkan dalam pembelajarannya, siswa terlibat secara aktif dalam pembelajaran mulai dari perencanaan sampai dengan evaluasi pembelajaran. Tiap kelompok diberikan subtopik yang berbeda menuntut masing-masing kelompok untuk memahami materi masing-masing. Berbeda dengan siswa yang diberi model pembelajaran langsung, siswa hanya menerima informasi yang diberikan guru. Hal ini sesuai dengan hasil penelitian Richardo (2015) yang menyatakan bahwa ada pengaruh model GI terhadap hasil belajar matematika siswa, artinya hasil belajar siswa yang diberi model GI lebih baik daripada yang diberi pembelajaran langsung. 
Hasil analisis anava dua jalan selanjutnya menyatakan bahwa hasil belajar matematika siswa dengan kemandirian belajar tinggi lebih baik daripada siswa dengan kemandirian belajar sedang dan rendah, namun hasil belajar matematika siswa dengan kemandirian mandiri sedang sama dengan siswa dengan kemandirian rendah. Hasil ini sama dengan hasil penelitian Jannah (2013) yang menyatakan bahwa prestasi belajar siswa dengan kemandirian tinggi lebih baik daripada siswa dengan kemandirian sedang dan rendah.

Siswa dengan kemandirian tinggi memiliki kemampuan yang baik dalam memanajemen dirinya dalam menentukan tujuan belajar, membuat perencanaan belajar, menentukan alokasi waktu yang diperlukan, serta menentukan strategi yang harus dicapai untuk mencapai tujuan tersebut. Selanjutnya siswa juga melakukan monitoring dan evaluasi belajarnya agar semakin dapat memerolah hasil yang lebih baik kedepannya. Siswa dengan kemandirian tinggi akan memeroleh hasil belajar yang lebih optimal pada setiap model pembelajaran yang diterimanaya.

Siswa dengan kemandirian sedang memiliki kemampuan manajemen dan kontrol diri yang lebih baik daripada siswa dengan kemandirian rendah. Seharusnya siswa dengan kemandirian sedang memiliki hasil belajar matematika yang lebih baik. Namun hasil penelitian menyatakan sebalik- nya. Hal ini disebabkan karena sebagian siswa pada saat pengisian angket merasa harus menunjukkan hal yang baik, bukan hal yang sebenarnya. Ini berakibat pada penetapan kategori tingkat kemandirian belajar yang kurang tepat. Berdasarkan pengamatan saat pembelajaran, beberapa siswa dengan kategori kemandirian tinggi menunjukkan sikap yang kurang mandiri dalam belajar, sebaliknya beberapa siswa dengan kemandirian belajar rendah menunjukkan kemandirian belajar yang baik.

Hasil analisis terakhir menyatakan bahwa tidak terdapat interaksi antara model pembelajaran dengan kemandirian belajar terhadap hasil belajar matematika siswa. Hasil penelitian ini sama dengan hasil penelitian Fitriana (2010) yang menyatakan tidak terdapat interaksi antara model pembelajaran kooperatif dengan kemandirian belajar siswa terhadap prestasi belajar matematika pada pokok bahasan bangun ruang sisi datar. Ini berarti bahwa pada kedua model, hasil belajar siswa dengan kemandirian belajar tinggi lebih baik daripada siswa dengan kemandirian belajar sedang dan rendah, sementara hasil belajar siswa dengan kemandirian belajar sedang sama dengan siswa dengan kemandirian belajar rendah. Begitupun dengan hasil belajar matematika pada tiap tingkatan pembelajaran, siswa yang diberi model pembelajaran GI memiliki hasil belajar 
matematika yang lebih baik daripada siswa yang diberi model pembelajaran langsung.

\section{E. SIMPULAN DAN SARAN}

Berdasarkan hasil analisis data dan pembahasan, dapat disimpulkan sebagai berikut. (1) Hasil belajar matematika siswa yang diberi model pembelajaran GI lebih baik daripada siswa yang diberi model pembelajaran langsung. (2) Hasil belajar matematika siswa dengan kemandirian belajar tinggi lebih baik daripada siswa dengan kemandirian belajar sedang dan rendah. Selanjutnya hasil belajar matematika siswa dengan kemandirian belajar sedang sama baik dengan siswa dengan kemandirian belajar rendah. (3) tidak ter- dapat interaksi antara model pembelajaran dan kemandirian belajar terhadap hasil belajar matematika.

Berdasarkan simpulan penelitian, disarankan kepada guru untuk menerapkan dapat pembelajaran kooperatif tipe GI untuk dapat meningkatkan hasil belajar matematika siswa khususnya pada materi persamaan garis lurus. Selanjutnya guru disarankan untuk memperhatikan kategori kemandirian belajar siswa dalam merancang pembelajaran sehingga dapat menghasilkan hasil belajar matematika yang optimal. Bagi peneliti yang akan melakukan penelitian lanjutan, untuk dapat lebih mempersiapkan segala hal dengan lebih baik agar diperoleh hasil yang sesuai.

\section{DAFTAR RUJUKAN}

Abdurahman, Mulyono. 2010. Pendidikan Bagi Anak Berkesulitan Belajar. Jakarta: Rhineka Cipta.

Fitriana, Laila. 2010. Pengaruh Model Pembelajaran Cooperative Tipe Group Investigation (GI) dan STAD Terhadap Prestasi Belajar Matematika Ditinjau dari Kemandirian Belajar Siswa. Tesis Pendidikan Matematika. Surakarta: UNS.

Jannah, Raodatul. 2013. Eksperimentasi Model Pembelajaran Kooperatif Tipe Structured Number Head (SNH) dan Numbered Heads Together (NHT) dengan Pendekatan Matematika Realistik pada Prestasi Belajar Matematika ditinjau dari Kemandirian Belajar Siswa Kelas VIII SMP Negeri di Kota Mataram Tahun Pelajaran 2012/2013. Tesis. Surakarta: UNS.

Lie, Anita. 2010. Cooperative Learning Mempraktikkan Cooperative Learning di RuangRuang Kelas. Jakarta: Grasindo

Richardo, Rino. 2015. Eksperimentasi Model Pembelajaran Kooperatif Tipe Investigasi Kelompok (Group Investigation) terhadap Hasil Belajar Matematika Berdasarkan Gaya Belajar Siswa. Jurnal Ilmiah Edu Research. 4(1). 35-42. 
Rusman. (2010). Model-Model Pembelajaran Mengembangkan Profesionalisme Guru. Jakarta: PT Rajagrafindo Persada.

Slameto. 2010. Belajar dan Faktor-Faktor yang Mempengaruhinya. Jakarta: Rineka Cipta.

Slavin, RE. 2005. Cooperative Learning: Teori, Riset, dan Praktik. Bandung: Nusa Media

Solikhah. 2014. Eksperimentasi Model Pembeajran Kooperatif tipe Group Investigation (GI) dan Numbered Head Together (NHT) pada Materi Garis Singgung Lingkaran ditinjau dari Kecerdasan Majemuk Siswa Kelas VIII SMP Negeri se-Kota Madiun Tahun Ajaran 2013/2014. Jurnal Elektronik Pembelajaran Matematika. 2(7). 727-739.

Song, L and Hill, J.R. 2007. A Conceptual for Understanding Self Directed Learning in Online Environments. Journal of Interactive Online Learning. 6(1). 27-41

Sugiyanto. 2009. Model-model Pembelajaran Inovatif. Surakarta: Yuma Pustaka. 